\title{
Efficacy of a criterion-driven transfusion protocol in patients having pediatric cardiac surgery
}

Yoshio Ootaki, MD, PhD

Masahiro Yamaguchi, MD, PhD

Naoki Yoshimura, MD, PhD

Shigeteru Oka, MD, PhD

Masahiro Yoshida, MD

Tomomi Hasegawa, MD

From the Department of Cardiothoracic Surgery, Kobe Children's Hospital, Kobe, Japan.

Received for publication April 1, 2003; revisions requested June 3, 2003; revisions received June 19, 2003; accepted for publication July 10, 2003.

Address for reprints: Yoshio Ootaki, MD, Department of Cardiothoracic Surgery, Kobe Children's Hospital, 1-1-1 Takakuradai, Suma-ku, Kobe, Hyogo 654-0081, Japan (E-mail: y.ootaki@nifty.ne.jp).

J Thorac Cardiovasc Surg 2004;127:953-8 $0022-5223 / \$ 30.00$

Copyright (C) 2004 by The American Association for Thoracic Surgery

doi:10.1016/S0022-5223(03)01318-7
Objectives: Low-hematocrit bypass is one technique used to prevent allogeneic transfusion during cardiopulmonary bypass. The purpose of this study is to determine the efficacy of a criterion-driven transfusion protocol and the effect of low-hematocrit bypass with moderate hypothermia in pediatric cardiac surgery.

Methods: Seventy-five children who underwent cardiopulmonary bypass with lowhematocrit bypass for repair of congenital heart disease were studied. Criteria for red blood cell transfusion included anemia with a hematocrit level of less than $15 \%$ during bypass and $20 \%$ after bypass. During cardiopulmonary bypass, venous oxygen saturation, hematocrit values, and regional cerebral oxygenation were continuously monitored. Arterial lactate levels were measured postoperatively.

Results: All patients had an uncomplicated perioperative course, and no perioperative death occurred. Twenty-two patients (29.3\%) received a transfusion, and 53 (70.7\%) patients did not. The hematocrit levels before and after modified ultrafiltration in the transfused group $(21.6 \pm 5.5 \%, 26.6 \pm 6.5 \%)$ were significantly higher than those in the nontransfused group $(18.9 \pm 3.7 \%, 23.1 \pm 4.1 \%)(P<.05)$. There was no significant difference between the group's arterial lactate levels immediately after admission to the intensive care unit and 1 day after the operation. The arterial lactate levels 6 hours after the admission to the intensive care unit for the nontransfused patients were higher than with the transfused patients $(4.3 \pm 3.0$ versus $2.5 \pm$ $1.5 \mathrm{mmol} / \mathrm{L},(P<.05)$. For arterial lactate level, the relation with patients' weight had the highest correlation $(\mathrm{R}=0.678, P<.0001)$.

Conclusions: A criterion-driven transfusion program can be effective, and lowhematocrit bypass with a hematocrit value below $20 \%$ may affect lactate production or clearance from the body.

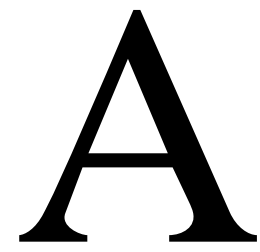

nemia remains one of the primary problems seen after cardiac surgery, especially in the pediatric age group. Whole blood and blood products are used for the treatment of anemia. However, this therapy can potentially cause a variety of complications, such as transfusion reactions, volume overload, infections, ${ }^{1,2}$ and increased hospital mortality ${ }^{3}$ and may have poor effects on longterm survival. ${ }^{4}$ Because of these risks, clinicians and surgeons are strongly motivated to minimize or avoid allogeneic transfusion.

Low-hematocrit bypass is one technique used to prevent allogeneic transfusion during cardiopulmonary bypass (CPB). After consistent success with low-hematocrit bypass in Jehovah's Witness patients, the lowest hematocrit levels being between $17.9 \%$ and $22.7 \%$ during $\mathrm{CPB},{ }^{5-8}$ many investigators ${ }^{9-11}$ reported that low-hematocrit bypass is effective in preventing allogeneic transfusion. These 
investigators also reported that the lowest safe hematocrit level was approximately $15 \%$. The risks of low-hematocrit bypass during deep hypothermic circulatory arrest are also reported. $^{12}$

The purpose of this study is to determine the efficacy of a criterion-driven transfusion protocol and the effect of low-hematocrit bypass with moderate hypothermia in pediatric cardiac surgery.

\section{Patients and Methods}

The study was approved by the local ethics committee and all parents gave written informed consent. A prospective, observational study was performed on 75 nonconsecutive children who underwent CPB for repair of congenital heart disease between January 1999 and August 1999 at Kobe Children's Hospital. Children who required deep hypothermic circulatory arrest or emergency surgery were excluded from this study.

There were $42(56.0 \%)$ boys and $33(44.0 \%)$ girls, with a mean age of $6.5 \pm 4.2$ years (range 4 months to 18 years), and a mean weight of $20.7 \pm 13.2 \mathrm{~kg}$ (range 4.0-69.3 kg). Forty-eight (64.0\%) patients had acyanotic heart disease, and $27(36.0 \%)$ patients had cyanotic heart disease.

Patients were placed on CPB with bicaval cannulations and a single aortic cannula. CPB was performed with a roller pump, and a hollow-fiber membrane oxygenator was used for gas exchange (Exceran HPO-20HC; MERA, Tokyo, Japan). The circuit was primed with 700 to $900 \mathrm{~mL}$ of acetate Ringer's solution depending on the weight of the patient. If the predicted hematocrit level after hemodilution was under $15 \%$, red blood cells were added to the priming solution. In these cases, the priming solution mixed with red blood cells was rinsed with $1000 \mathrm{~mL}$ of bicarbonate Ringer's solution using a polymethylmethacrylate (PMMA) hemofilter (Hemofeel-CH-0.3SL, TORAY; Tokyo, Japan) before CPB. CPB was instituted at a flow rate of 2.2 to $2.6 \mathrm{~L} \cdot \mathrm{min}^{-1} \cdot \mathrm{m}^{-2}$, and the perfusate was cooled to induce moderate hypothermia $\left(26^{\circ} \mathrm{C}\right.$ to $32^{\circ} \mathrm{C}$ ). Blood gas management was performed using the $\mathrm{pH}$-stat strategy. Before CPB was initiated, $15 \mathrm{~mL} / \mathrm{kg}$ of autologous blood was collected from the right atrial cannula, and replaced with the same amount of hydroxyethylated starch. The autologous blood was returned to the patient after modified ultrafiltration (MUF). Myocardial preservation was achieved with intermittent cold blood cardioplegia composed of a crystalloid cardioplegic solution and oxygenated blood from the oxygenator. The blood cardioplegic solution was returned to the cardiotomy reservoir during CPB. Conventional ultrafiltration (CUF) and MUF were carried out with a PMMA hemofilter. CUF was begun during the rewarming phase of CPB with its rate adjusted to reach a cardiotomy reservoir level that approached zero at the termination of CPB. If red blood cells were transfused during CPB, dilutional ultrafiltration (DUF) was performed with $1000 \mathrm{~mL}$ of bicarbonate Ringer's solution as Bando and associates reported. ${ }^{13}$ MUF was started after the termination of CPB with an ultrafiltration rate of 15 to $20 \mathrm{~mL} / \mathrm{kg}$ in 15 minutes, as we previously reported. ${ }^{14}$ The heparinization was neutralized by protamine sulfate until the activated coagulation time had normalized. The remaining blood in the CPB circuit was returned to the patient within the operative day. Postoperative drainage was collected in a water-sealed drainage system; how- ever, the blood that was shed was not reinfused. Maximal dose of dopamine and dobutamine, intubation time, and days spent in the intensive care unit (ICU) were recorded.

Criteria for red blood cell transfusion included anemia with a hematocrit level of less than $15 \%$ during CPB and $20 \%$ after CPB. We monitored mixed venous oxygen saturation $\left(\mathrm{SvO}_{2}\right)$ during CPB and maintained the value above $50 \%$. If we had difficulty maintaining the $\mathrm{SvO}_{2}$ above 50\%, despite increasing the pump flow or oxygen concentration during $\mathrm{CPB}$, we decided to transfuse the autologous blood or allogeneic blood. If postoperative hemodynamic instability persisted despite sufficient inotropic support, we decided to transfuse red blood cells even when the hematocrit level was above $20 \%$. We did not transfuse platelets or fresh frozen plasma before red blood cell transfusion in this study.

Data used in these analysis included patient age; sex; weight; CPB time; total cardiac ischemic time; the lowest rectal temperature; the lowest $\mathrm{SvO}_{2}$ during $\mathrm{CPB}$; alveolar arterial gradient $\left(\mathrm{AaDO}_{2}\right)$ just after admission to the ICU; postoperative blood loss. Arterial blood hematocrit levels before CPB, lowest hematocrit levels during $\mathrm{CPB}$, hematocrit levels before MUF, after MUF, just after admission to the intensive care unit (ICU), and 1 day after the operation were analyzed. The arterial lactate levels were measured by Lactate Pro (Arkray Factory Inc., KDK Corporation, Kyoto, Japan) just after admission to the ICU, 6 hours after admission to the ICU, and 1 day after the operation. The venous oxygen saturation and hematocrit values were continuously monitored through $\mathrm{CPB}$ by an optical hematocrit and $\mathrm{SvO}_{2}$ sensor (Crit-Line monitor, In-Line Diagnostics, Riverdale, Utah).

In 17 patients, we monitored regional cerebral oxygenation using near-infrared spectroscopy (TOS 96; Tostec, Tokyo, Japan), in which two probes were placed on the forehead bilaterally. With this system, changes in intracranial oxygenation were recorded every second during the operation. If we had difficulty maintaining the regional cerebral oxygen saturation above $50 \%$, in conjunction with the assessment by the $\mathrm{SvO}_{2}$, we also decided to transfuse the autologous blood or allogeneic blood.

Statistical analyses were performed with a statistical analysis program (Statview 5.0; Cricket Software, Philadelphia, Pa). All values were expressed as mean \pm standard deviation $(\mathrm{SD})$. An unpaired Student $t$ test, a $\chi^{2}$ test for independence, and a Fisher exact probability test were used to assess the differences between the two groups. A paired Student $t$ test was used assess the difference between postoperative changes of arterial lactate levels in each group. The correlation between differences in lactate levels and parameters were calculated by linear regression analysis.

\section{Results}

All patients had an uncomplicated perioperative course, and no perioperative death occurred. All patients were discharged from the hospital in good condition. Twenty-two of 75 study patients $(29.3 \%)$ received a transfusion during their operation or stay in the ICU. Of the 22 patients who received a transfusion, 9 patients received transfusions in the form of the priming solution because of their low body weight, 7 patients were transfused to maintain hematocrit level or mixed venous oxygen saturation, and 6 patients were transfused because of hemodynamic instability after 
the termination of CPB. The clinical characteristics and surgical data in the patients with transfusion (group 1) and without transfusion (group 2) are shown in Table 1. The transfused patients were younger, smaller, and more likely to have had cyanotic heart disease. Additionally, the transfused patients had longer CPB time, longer total cardiac ischemic time, lower rectal temperature, lower $\mathrm{SvO}_{2}$, higher AaDo2, and required a larger amount of inotropic agents, longer intubation time, and longer stays in the ICU.

The perioperative hematocrit levels for patients in both groups are shown in Figure 1. The hematocrit levels before MUF and after MUF in group $1(21.6 \% \pm 5.5 \%, 26.6 \% \pm$ $6.5 \%)$ were significantly higher than that in group $2(18.9 \%$ $\pm 3.7 \%, 23.1 \% \pm 4.1 \%)(P<.05)$. However, there was no significant difference between the groups in the other data points.

The postoperative arterial lactate levels for patients in both groups are shown in Figure 2. The arterial lactate level 1 day after the operation $(1.7 \pm 1.0 \mathrm{mmol} / \mathrm{L})$ showed a significant decrease compared with the baseline $(2.6 \pm 1.7$ $\mathrm{mmol} / \mathrm{L})$ in group $1(P<.05)$. The arterial lactate levels 6 hours after admission to the ICU $(4.3 \pm 3.0 \mathrm{mmol} / \mathrm{L})$ and 1 day after the operation $(2.0 \pm 2.1 \mathrm{mmol} / \mathrm{L})$ had significant differences when compared with the baseline $(3.0 \pm 2.1$ $\mathrm{mmol} / \mathrm{L})$ in group $2(P<.05)$. Although there was no significant difference in the arterial lactate levels just after admission to the ICU and 1 day after the operation between the groups, the arterial lactate level 6 hours after admission to the ICU in group $2(4.3 \pm 3.0 \mathrm{mmol} / \mathrm{L})$ was significantly higher than that in group $1(2.5 \pm 1.5 \mathrm{mmol} / \mathrm{L})(P<.05)$.

The correlation between the lowest hematocrit level and the arterial lactate level 6 hours after admission to the ICU in all patients was not strong $(\mathrm{R}=0.428, P=.0019)$. The correlation coefficients for the relation between each of the independent variables and the arterial lactate level 6 hours after admission to the ICU in group 2 are listed in Table 2 . For arterial lactate level, the relation with patients' weight had the highest correlation ( $\mathrm{R}=0.678, P<.0001)$ (Figure 3).

\section{Discussion}

During moderate hemodilution, total body oxygen delivery is maintained because hemodilution reduces blood viscosity and vascular resistance, resulting in an increase in tissue blood flow under both $\mathrm{CPB}^{15}$ and non-CPB conditions. ${ }^{16}$ Cook and associates ${ }^{17}$ reported that physiologically important changes in cerebral oxygen supply might occur at hematocrit levels of $12 \%$ in $18^{\circ} \mathrm{C}, 15 \%$ in $28^{\circ} \mathrm{C}$, and $18 \%$ in $38^{\circ} \mathrm{C}$ under CPB conditions. Therefore, our criteria for red blood cell transfusion, including anemia with a hematocrit level less than $15 \%$ during CPB and $20 \%$ after CPB, were reasonable to prevent neurologic complications. Baraka and associates ${ }^{18}$ reported the correlation between $\mathrm{SvO}_{2}$ and
TABLE 1. Patient characteristics and surgical data

\begin{tabular}{|c|c|c|c|}
\hline Variable & Group 1 & Group 2 & $P$ value \\
\hline No. of patients & 22 & 53 & \\
\hline Age (y) & $3.2 \pm 2.5$ & $7.9 \pm 4.0$ & $<0.01$ \\
\hline Sex (male/female) & $10 / 12$ & $32 / 21$ & 0.24 \\
\hline Weight $(\mathrm{kg})$ & $11.2 \pm 5.6$ & $24.6 \pm 13.4$ & $<0.01$ \\
\hline $\begin{array}{l}\text { Diagnosis } \\
\quad \text { (acyanotic/cyanotic) }\end{array}$ & $7 / 15$ & $41 / 12$ & $<0.01$ \\
\hline CPB time (min) & $225 \pm 74$ & $142 \pm 74$ & $<0.01$ \\
\hline $\begin{array}{l}\text { Total cardiac ischemic time } \\
\text { (min) }\end{array}$ & $105 \pm 44$ & $62 \pm 48$ & $<0.01$ \\
\hline $\begin{array}{l}\text { Lowest rectal temperature } \\
\left({ }^{\circ} \mathrm{C}\right)\end{array}$ & $27.0 \pm 1.4$ & $29.7 \pm 2.6$ & $<0.01$ \\
\hline Lowest $\mathrm{SvO}_{2}(\%)$ & $57.0 \pm 7.8$ & $64.5 \pm 15.3$ & $<0.05$ \\
\hline $\mathrm{A}-\mathrm{aDO}_{2}(\mathrm{~mm} \mathrm{Hg})$ & $214.3 \pm 97.6$ & $143.7 \pm 53.9$ & $<0.01$ \\
\hline $\begin{array}{l}\text { Postoperative blood loss } \\
\text { (mL) } 6 \mathrm{~h}\end{array}$ & $112.9 \pm 67.9$ & $95.5 \pm 79.8$ & 0.37 \\
\hline $\begin{array}{l}\text { Postoperative blood loss } \\
\text { (mL) } 24 \mathrm{~h}\end{array}$ & \multicolumn{2}{|c|}{$263.8 \pm 174.6207 .6 \pm 156.4$} & 0.18 \\
\hline $\begin{array}{l}\text { Maximal dose of dopamine } \\
\qquad\left(\mu \mathrm{g} \cdot \mathrm{kg}^{-1} \cdot \min ^{-1}\right)\end{array}$ & $9.2 \pm 0.5$ & $7.2 \pm 0.4$ & $<0.01$ \\
\hline $\begin{array}{l}\text { Maximal dose of dobutamine } \\
\left(\mu \mathrm{g} \cdot \mathrm{kg}^{-1} \cdot \min ^{-1}\right)\end{array}$ & $5.6 \pm 0.9$ & $1.6 \pm 0.4$ & $<0.01$ \\
\hline Intubation time $24 \mathrm{~h}<$ & $10(45.5 \%)$ & $4(7.5 \%)$ & $<0.01$ \\
\hline ICU stay 2 days $<$ & $20(90.9 \%)$ & $23(43.5 \%)$ & $<0.01$ \\
\hline
\end{tabular}

Data are given as mean \pm SD where indicated.

changes of body temperature, perfusion flow, and hematocrit levels. Croughwell and associates ${ }^{19}$ reported that there is a marked increase in cognitive impairment, when jugular venous oxygen saturation is less than $50 \%$ during rewarming. Therefore, our criterion to transfuse red blood cells when the $\mathrm{SvO}_{2}$ level was less than $50 \%$ was also reasonable.

However, the arterial lactate level 6 hours after admission to the ICU in group 2 was significantly higher than that in group 1 . The patients in group 1 had a longer CPB time, longer total cardiac ischemic time, and lower $\mathrm{SvO}_{2}$. The patients in group 1 also required a larger amount of inotropic agents, longer intubation time, and longer stays in the ICU. The longer CPB time might be a cause for transfusion because of hemolysis or blood loss during CPB. Many investigators reported ${ }^{20-24}$ that patients with high lactate levels tend to require a longer CPB time. Lower $\mathrm{SvO}_{2}$ during CPB can also lead to high lactate levels. ${ }^{22} \mathrm{We}$ believe that the patients in group 1 did not have elevated lactate levels due to red blood cell transfusion during CPB. In the case of a complex congenital heart defect, we tend to transfuse just after the direct confirmation of the intracardiac anatomy, and after the determination of the operative procedures according to the complex defect. Therefore, the period during which the hematocrit value is maintained at its lowest level in group 1 might be shorter than that in group 2. The patients in group 2 might have longer periods with the lowest hematocrit level. Furthermore, longer CPB time might result in the comparatively lower body temper- 




Figure 1. Perioperative changes in hematocrit levels. ${ }^{*} P<.05$, group 1 vs group 2.

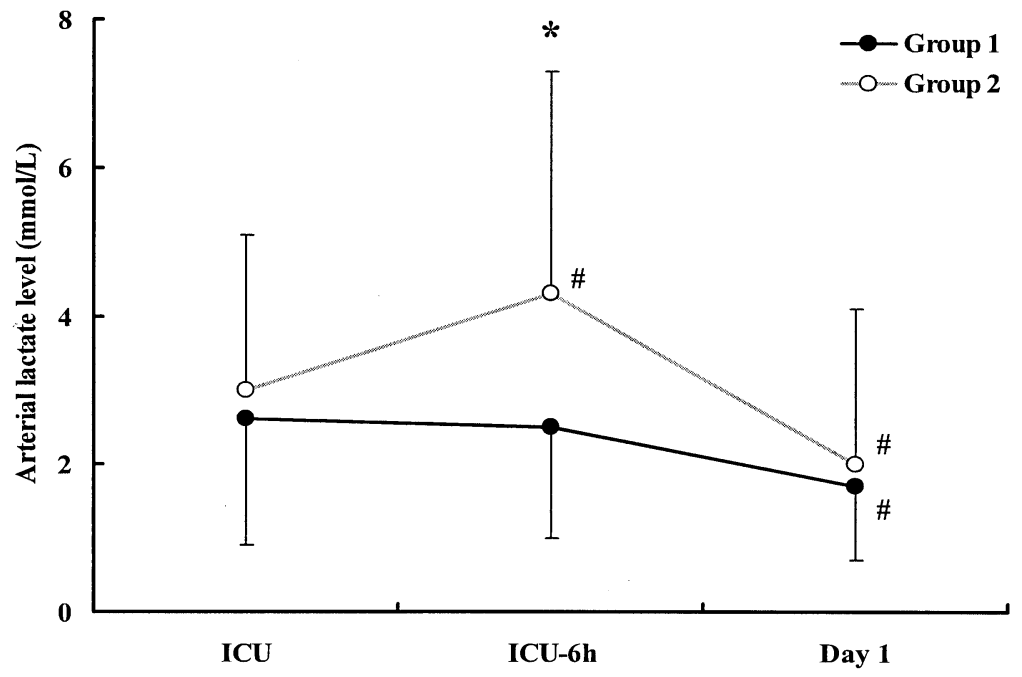

Figure 2. Postoperative changes in arterial lactate levels. ${ }^{*} P<.05$, group 1 vs group $2 . \# P<.05$, vs baseline.

ature in the patients with group 1 . Not only will a higher hematocrit level have a greater potential to deliver oxygen but also a lower body temperature might lead the body to require less oxygen after $\mathrm{CPB}$.

The arterial lactate level in group 2 rose 6 hours after admission to the ICU and fell below the level just after admission to the ICU, at 1 day after the operation, while the peak lactate level in group 1 was just after admission to the ICU, and fell along the time course. Ariza and associates ${ }^{25}$ and Routsi and associates ${ }^{26}$ reported that the peak lactate level was measured 3 to 12 hours after admission to the ICU, while $\mathrm{Li}$ and associates ${ }^{24}$ reported that the peak level was measured just after admission to the ICU. The progressive elevation in arterial lactate levels during the postoper- ative period could be caused by the effects of the increasing metabolic rate through spontaneous rewarming, emergence from anesthesia, and spontaneous recovery of myocardial function. Furthermore, it could be caused by the tissue washout of lactate after an increase in tissue perfusion. The splanchnic circulation could be a cause of elevation in lactate level ${ }^{27}$ during the postoperative period. Finally, the elevation in lactate could be due to impaired clearance by the liver. Although we did not confirm the liver clearance after CPB in this study, the hematologic studies revealed no significant liver dysfunction in either group.

Our data demonstrated that the linear relationship between the arterial lactate level 6 hours after admission to the ICU in group 2 and the body weight showed the most 
TABLE 2. Multiple regression analyses of association between the arterial lactate levels six hours after the admission to the ICU and the patient characteristics, and the surgical data in group 2

\begin{tabular}{lcr}
\hline & \multicolumn{2}{c}{ Lactate ICU-6 h } \\
\cline { 2 - 3 } Variable & Coefficient & $\boldsymbol{P}$ value \\
\hline Age & 0.677 & $<.0001$ \\
Weight & 0.678 & $<.0001$ \\
CPB time & 0.149 & .3941 \\
Total cardiac ischemic time & 0.148 & .3946 \\
Lowest hematocrit & 0.614 & $<.0001$ \\
Lowest rectal temperature & 0.041 & .8217 \\
Lowest Sv0 $\mathrm{S}_{2}$ & 0.263 & .1272 \\
A-aDo & 0.148 & .3954 \\
Postoperative blood loss, $6 \mathrm{~h}$ & 0.318 & .0625 \\
Postoperative blood loss, 24 $\mathrm{h}$ & 0.373 & .0271 \\
Maximal dose of dopamine & 0.029 & .8671 \\
Maximal dose of dobutamine & 0.155 & .3729 \\
Intubation time & 0.087 & .6183 \\
ICU stay & 0.100 & .5675 \\
\hline
\end{tabular}

significant correlation among the various variables. Interestingly, the reports ${ }^{25,26}$ in which the peak lactate level was measured 3 to 12 hours after admission to the ICU was on a study on the adult age group, whereas the report ${ }^{24}$ in which the peak level was measured just after admission to the ICU was on a study of patients from the small children age group ( 2 months to 15 years; median, 3.75 years). The progressive elevation in arterial lactate levels during the postoperative period in group 2 might suggest that there was lactate accumulation during low-hematocrit $\mathrm{CPB}$ and the difference in the central body temperature after CPB was attributable to the body weight. Further investigations will be needed to clarify the progressive elevation in arterial lactate levels during the postoperative period.

We rinsed the priming blood solution or performed DUF when we transfused red blood cells, because transfusion of packed red blood cells leads to a severe burden of hydrogen ions, carbon dioxide, potassium, glucose, and lactic acid. ${ }^{28}$ Haynes and associates ${ }^{29}$ also reported that allogeneic transfusion increased the inflammatory response. Although longer CPB time and longer total cardiac ischemic time might have led to the elevation of $\mathrm{A}-\mathrm{aDo}_{2}$ in group 1 , rinsing the blood might remove lactate during CPB. This process might affect the lactate level and lead to a decrease during the postoperative period.

In our study, venous oxygen saturation, hematocrit values, and regional cerebral oxygenation were continuously monitored through CPB. Although the cerebral circulation is not representative of whole body physiology, the brain has the highest oxygen demand, lowest oxidative reserve, and is more prone to significant damage during CPB than any other organ, especially during low-hematocrit bypass.



Figure 3. The relationship between body weights and arterial lactate levels 6 hours after admission to the ICU in group 2.

Several investigators reported the importance and usefulness of cerebral monitoring during cardiac surgery. ${ }^{30,31}$ Regional cerebral oxygenation status may not always reflect the postoperative neurologic damage because the minor changes may only be detected by magnetic resonance imaging. ${ }^{32}$ We could not prove the effectiveness of this technique with statistical significance in this study because of the limited number of patients, the method of fitting, the laterality, and the individual difference of the circumference of the head. However, this type of serial monitoring might be necessary during low-hematocrit bypass to prevent neurologic damage.

Mild hyperlactemia is relatively common after CPB, typically with a range of 2 to $4 \mathrm{mmol} / \mathrm{L} \cdot{ }^{24-26}$ Duke and associates $^{22}$ reported that the odds ratios for major adverse events if the blood lactate level was greater than $4 \mathrm{mmol} / \mathrm{L}$ at 4 and 8 hours were 8.3 and 9.3, respectively. Hatherill and associates ${ }^{33}$ reported that an initial lactate level of 6 $\mathrm{mmol} / \mathrm{L}$ had the best predictive value for mortality. Most patients of our study did not reach such high lactate levels and did not have a complicated perioperative course under our transfusion criteria. However, further investigation will be needed to clarify the effects of low-hematocrit bypass.

The obvious limitation of our study is that it was a prospective, observational study, not a prospective, randomized study. Therefore, the patient characteristics and surgical data were different between the two groups. The usefulness and the role of cerebral monitoring remain uncertain. Further studies will be necessary to clarify the effect of low-hematocrit bypass. 
In conclusion, a criterion-driven transfusion program can be effective, and the arterial lactate level after low-hematocrit bypass without transfusion is higher than that with transfusion despite the longer CPB time. Although the patients did not have complicated perioperative courses, lowhematocrit bypass with a hematocrit value below $20 \%$ may affect lactate production or clearance from the body.

We thank Michael Kopcak for his editorial advice.

\section{References}

1. Dodd RY. The risk of transfusion-transmitted infection. $N$ Engl J Med. 1992;327:419-21.

2. Kuehnert MJ, Roth VR, Haley NR, et al. Transfusion-transmitted bacterial infection in the United States, 1998 through 2000. Transfusion. 2001;41:1493-9.

3. Michalopoulos A, Tzelepis G, Dafni U, Geroulanos S. Determinants of hospital mortality after coronary artery bypass grafting. Chest. 1999; 115:1598-603.

4. Engoren MC, Habib RH, Zacharias A, Schwann TA, Riordan CJ, Durham SJ. Effect of blood transfusion on long-term survival after cardiac operation. Ann Thorac Surg. 2002;74:1180-6.

5. Henling CE, Carmichael MJ, Keats AS, Cooley DA. Cardiac operation for congenital heart disease in children of Jehovah's Witnesses. J Thorac Cardiovasc Surg. 1985;89:914-20.

6. Stein JI, Gombotz H, Rigler B, Metzler H, Suppan C, Beitzke A. Open heart surgery in children of Jehovah's Witnesses: extreme hemodilution on cardiopulmonary bypass. Pediatr Cardiol. 1991;12:170-4.

7. van Son JA, Hovaguimian H, Rao IM, et al. Strategies for repair of congenital heart defects in infants without the use of blood. Ann Thorac Surg. 1995;59:384-8.

8. Chikada M, Furuse A, Kotsuka Y, Yagyu K. Open-heart surgery in Jehovah's Witness patients. Cardiovasc Surg. 1996;4:311-4.

9. Kawaguchi A, Bergsland J, Subramanian S. Total bloodless open heart surgery in the pediatric age group. Circulation. 1984;70(Suppl I):I30-7.

10. Kurth CD, Steven JM, Nicolson SC, Jacobs ML. Cerebral oxygenation during cardiopulmonary bypass in children. $J$ Thorac Cardiovasc Surg. 1997;113:71-8.

11. Masuda H, Moriyama Y, Hisatomi K, et al. Preoperative autologous donation of blood for a simple cardiac anomaly: analysis of children weighing under twenty kilograms. J Thorac Cardiovasc Surg. 2000; 120:783-9.

12. Duebener LF, Sakamoto T, Hatsuoka S, et al. Effects of hematocrit on cerebral microcirculation and tissue oxygenation during deep hypothermic bypass. Circulation. 2001;104(Suppl I):I-260-4.

13. Bando K, Vijay P, Turrentine MW, et al. Dilutional and modified ultrafiltration reduces pulmonary hypertension after operations for congenital heart disease: a prospective, randomized study. $J$ Thorac Cardiovasc Surg. 1998;115:517-25.

14. Ootaki Y, Yamaguchi M, Oshima Y, Yoshimura N, Oka S. Effects of modified ultrafiltration on coagulation factors in pediatric cardiac surgery. Surg Today. 2002;32:203-6.

15. Cook DJ, Orszulak TA, Daly RC, MacVeigh I. Minimum hematocrit for normothermic cardiopulmonary bypass in dogs. Circulation. 1997; 96(Suppl II):II-200-4.

16. Messmer K. Hemodilution. Surg Clin North Am. 1975;55:659-78.

17. Cook DJ, Orszulak TA, Daly RC. Minimum hematocrit at differing cardiopulmonary bypass temperatures in dogs. Circulation. 1998; 98(Suppl II):II-170-5.

18. Baraka A, Baroody M, Haroun S, et al. Continuous venous oximetry during cardiopulmonary bypass: influence of temperature changes, perfusion flow, and hematocrit levels. J Cardiothorac Anesth. 1990; 4:35-8.

19. Croughwell ND, Newman MF, Blumenthal JA, et al. Jugular bulb saturation and cognitive dysfunction after cardiopulmonary bypass. Ann Thorac Surg. 1994;58:1702-8.

20. Himpe D. Anion gap, lactate, and acid-base status after cardiac surgery. Crit Care Med. 1993;21:807-8.

21. Siegel LB, Dalton HJ, Hertzog JH, Hopkins RA, Hannan RL, Hauser GJ. Initial postoperative serum lactate levels predict survival in children after open heart surgery. Intensive Care Med. 1996;22:1418-23.

22. Duke T, Butt W, South M, Karl TR. Early markers of major adverse events in children after cardiac operations. J Thorac Cardiovasc Surg. 1997; 114:1042-52.

23. Munoz R, Laussen PC, Palacio G, Zienko L, Piercey G, Wessel DL. Changes in whole blood lactate levels during cardiopulmonary bypass for surgery for congenital cardiac disease: an early indicator of morbidity and mortality. J Thorac Cardiovasc Surg. 2000;119:155-62.

24. Li J, Schulze-Neick I, Lincoln C, et al. Oxygen consumption after cardiopulmonary bypass surgery in children: determinants and implications. J Thorac Cardiovasc Surg. 2000;119:525-33.

25. Ariza M, Gothard JW, Macnaughton P, Hooper J, Morgan CJ, Evans TW. Blood lactate and mixed venous-arterial $\mathrm{PCO} 2$ gradient as indices of poor peripheral perfusion following cardiopulmonary bypass surgery. Intensive Care Med. 1991;17:320-4.

26. Routsi C, Vincent JL, Bakker J, et al. Relation between oxygen consumption and oxygen delivery in patients after cardiac surgery. Anesth Analg. 1993;77:1104-10.

27. Landow L. Splanchnic lactate production in cardiac surgery patients. Crit Care Med. 1993;21:S84-91.

28. Sumpelmann R, Schurholz T, Thorns E, Hausdorfer J. Acid-base, electrolyte and metabolite concentrations in packed red blood cells for major transfusion in infants. Paediatr Anaesth. 2001;11:169-73.

29. Haynes SL, Wong JC, Torella F, Dalrymple K, Pilsworth L, McCollum CN. The influence of homologous blood transfusion on immunity and clinical outcome in aortic surgery. Eur J Vasc Endovasc Surg. 2001;22:244-50.

30. Sakamoto T, Hatsuoka S, Stock UA, et al. Prediction of safe duration of hypothermic circulatory arrest by near-infrared spectroscopy. J Thorac Cardiovasc Surg. 2001;122:339-50.

31. Yamashita K, Kazui T, Terada H, Washiyama N, Suzuki K, Bashar AH. Cerebral oxygenation monitoring for total arch replacement using selective cerebral perfusion. Ann Thorac Surg. 2001;72:503-8.

32. Mahle WT, Tavani F, Zimmerman RA, et al. An MRI study of neurological injury before and after congenital heart surgery. Circulation. 2002;106(Suppl I):I-109-14.

33. Hatherill M, Sajjanhar T, Tibby SM, et al. Serum lactate as a predictor of mortality after paediatric cardiac surgery. Arch Dis Child. 1997;77: $235-8$. 